\title{
Open Appendectomy in Children: Double Ligation Versus Stump Inversion
}

\author{
Murat Sanal \\ Innsbruck Medical University, Department of pediatric Surgery, Anichstr. 35, 6020 Innsbruck, Austria
}

\begin{abstract}
Background: The aim of the study is to draw a comparison between two appendectomy techniques of open appendectomy procedure entitled double ligation and stump inversion.

Methods: The study was designed retrospectively at two different points in time when one of these two techniques was performed in our department. At the first time period in 2008 (Group A) 166 double ligation appendectomies were performed in comparison to the latter in 2011 (GroupB) where 202 stump inversion have been carried out. The main outcome measures were postoperative complications and they were assessed according to the intention to- treat analysis principle.

Results: There was no mortality and overall complication rate was similar in both groups. A total number 60 simple wound infections treated with wound dressing. The cases of deep wound infections and abdominal abscesses underwent antibiotic treatment and four children in group B required reoperation. The only statistically significant outcome is that the period of hospital stay of groupB turned out to be longer than groupA.

Conclusion: Considering the main surgical principle of "the preference of the more simple technique", we believe that; in performance of an open appendectomy, the preference of a double ligation technique would be more appropriate.
\end{abstract}

\section{Introduction}

Appendectomy is one of the most common surgical treatments even in children. In literature, treatment of open appendectomy is well described and there are mainly two different techniques for the appendix stump management; simple ligation and stump inversion [1-5].

Thought of the group for stump inversion includes; open stump become the source of contamination and there would be greater risk of adhesions on the caecal region. On the other hand; authors for simple ligation supported this technique because of the fact that it is an easer version amongst the two.In literature, many studies on simple ligation versus stump inversion puts forward that there is no significant difference in between these two techniques $[2,4,5]$.

However, there is limited publication on children regarding to the simple ligation versus stump inversion.

In our hospital both techniques are being used frequently.

In order to demonstrate which technique is the better one, we performed this study aimed at re-evaluating this topic in light of our own findings on childhood.

\section{Materials \& Method}

The study was designed retrospectively at two different points in time when one of these two techniques by open appendectomy were performed in our department.

Together 386 children mean age 12.5 years were included. At the first time period 2014 (Group A) 166 double ligation appendectomy were performed in comparison 2015(GroupB) 202 stumpinversiontechnigues have been carried out.

Research Ethics Board approval (Application No: AN2014-0117 $336 / 4.2$ ) was obtained to perform the retrospective study.

\author{
Publication History: \\ Received: March 03, 2016 \\ Accepted: June 10, 2017 \\ Published: June 13, 2017
}

Keywords:

Appendectomy, Appendicitis, Childhood, Stump inversion
The diagnosis of appendicitis was made of the history of abdominal pain, right lower quadrant guarding and tenderness on physical examination and all patients underwent abdominal sonography .

In order for the surgical technique to be a standard one, the McBurney incision was used in all patients.

On group A the appendix stump was ligated twice with vicryl. On group B appendix stump was as well ligated by the same material of vicryl and inverted with purse string suture.

Due to the fact that we are an educational hospital most of the cases were operated by residence in accompany of senior surgeons.

The postoperative care included a standardized postoperative regimen with pain treatment, bowel sounds and flatus were criterium for oral intake. The patients first started with a clear liquid diet and later on advanced to a regular diet in time of toleration.

Our criterion of hospital discharge of the patients are; an intake of normal diet, abscence of pain or fever complaint, defecation and normalization of the leukocyt values.

The outcomes were assessed according to the intention-to-treat analysis principle. All patients were followed for a minimum of 6 months period in which they are invited to the clinic periodically, in two months intervals, related to concerning late complications.

"Corresponding Author: Dr. Murat Sanal, Innsbruck Medical University, Department of pediatric Surgery, Anichstr. 35, 6020 Innsbruck, Austria, Tel: +43 512504 80774; E-mail: murat.sanal@tirol-kliniken.at

Citation: Sanal M (2017) Open Appendectomy in Children: Double Ligation Versus Stump Inversion. Int J Surg Surgical Porced 2: 120. doi: https://doi. org/10.15344/2456-4443/2017/120

Copyright: () 2017 Sanal. This is an open-access article distributed under the terms of the Creative Commons Attribution License, which permits unrestricted use, distribution, and reproduction in any medium, provided the original author and source are credited. 
Citation: Sanal M (2017) Open Appendectomy in Children: Double Ligation Versus Stump Inversion. Int J Surg Surgical Porced 2: 120. doi: https:/doi. $\operatorname{org} / 10.15344 / 2456-4443 / 2017 / 120$

Page 2 of 3

Complications such as simple and deep wound infections, abdominal abscesses and postoperative hospital stay were recorded.

Spontaneous discharge of pus or discharge of pus after incision out of the the wound were registered as infection. However, the simple wound infections recovered only by wound dressing were not taken under evaluation.

Deep wound infections that means infection of subcutis and subfacial region without facia detachment were verified by sonography and treated with amoxacilline + clavulanic acid and wound dressing. The children with abdominal abscesses were treated with piperacillin tazobactam and four of them have got reoperation.

\section{Results and Discussion}

The characteristics of the patients, distrubition of sex and age in both groups is presented in table 1. In group A 166 and in group B 202 patients were included the study.

After a median follow up of 6 months, 60 wound complications ( $15.78 \%$ ) had occured. Both groups were nearly equal in occurance of post operative complications. In group A there was no any significant higher rate of complications $29.7 \%$ vs $25.6 \%$ in group B ( $p=0.25)$.

There was no patient with failure to invert the appendicular stump however we observed that inversion in phlegmonous appendicitis may be difficult because of the edema and inflammatory tissue structures.

\begin{tabular}{|l|l|l|}
\hline $\mathrm{n}=368$ & $\begin{array}{l}\text { Group A } \\
(\mathrm{n}=166)\end{array}$ & $\begin{array}{l}\text { Group B } \\
(\mathrm{n}=202)\end{array}$ \\
\hline Mean age & 13 & 12.5 \\
\hline Sex & $72 \mathrm{~m}(43 \%), 94 \mathrm{f}(57 \%)$ & $82 \mathrm{~m}(41 \%), 120 \mathrm{f}(59 \%)$ \\
\hline
\end{tabular}

Table 1: Patients Characteristics.

There was no mortality, no bleeding. 17 children with deep wound infection and abdominal abscess were treated antibiotically, 4 of them required reintervention. 4 patients of the group B with abdominal abscess required reoperation. Three have got relaparotomy and one patient got healed due to placement of pig tail ( Table 2). There were no adhessive ileus complications during follow up.

\begin{tabular}{|l|l|l|}
\hline & $\begin{array}{l}\text { Group A } \\
(\mathrm{n}=166)\end{array}$ & $\begin{array}{l}\text { Group B } \\
(\mathrm{n}=202)\end{array}$ \\
\hline Deep wound infection & 3 & 8 \\
\hline Abdominal Abscess & 2 & 4 \\
\hline Antibiosis & 5 & 12 \\
\hline Reoperation & 0 & 4 \\
\hline
\end{tabular}

Table 2: omplications \& Reinterventions

Pathological examination of the appendices revealed $5.7 \%$ appendicitis catarhhalis or chronica, $46.4 \%$ appendicitis acuta, 40.4 $\%$ appendicitis phlegmonousa and 27 patients had a perforated appendicitis (Table 3). We have seen the perforation site most often in the middle third of the appendix.

The three children out of perforated appendicitis were under the age of 5 .
The complication rate between two groups was not statistically significant.

\begin{tabular}{|l|l|l|}
\hline Histology & $\begin{array}{l}\text { Group A } \\
(\mathrm{n}=166)\end{array}$ & $\begin{array}{l}\text { Group B } \\
(\mathrm{n}=202)\end{array}$ \\
\hline Catarhhalisorchronica & 9 & 12 \\
\hline Phlegmonous & 75 & 74 \\
\hline Acuta & 75 & 96 \\
\hline Perforated & 7 & 20 \\
\hline
\end{tabular}

Table 3: Histological findings.

Statistical analysis revealed a significant difference in hospital stay which were 5,11 day of group A versus 3,64 day Group B ( $p=0,003)$ (Table 4).

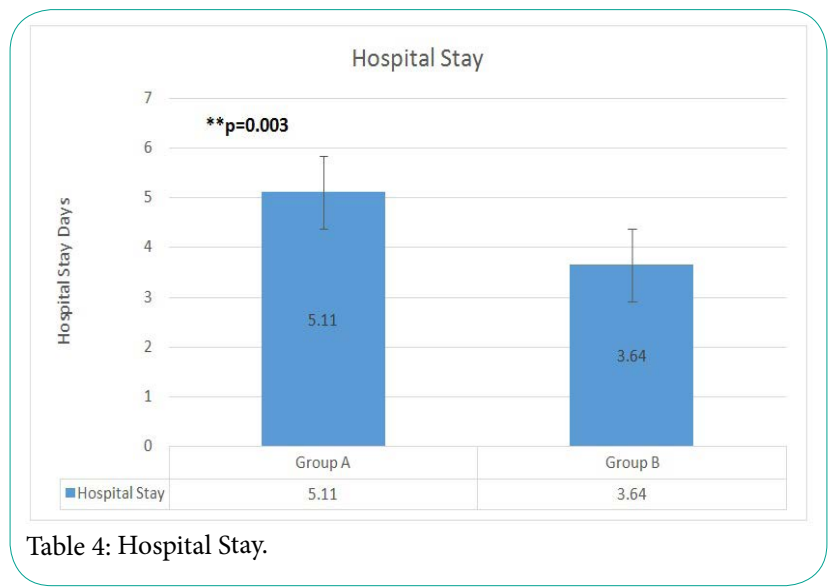

In our opinion, to confirm the scientific explanation of this finding, further research with a higher patient number is required.

Appendicitis is the most common surgical disease even by pediatric population.

Appendectomy is catagorized as a simple operation and it is generally entrusted to residents [1].

Neverthless; the appendectomy shall not be underestimated by leaving the potantial complications of each surgical procedure aside, especially in educational institutions like ours the vitality of the standardization of the appendectomy shall be kept in mind.

One of the historical contoversies of the open technique involves the management of the appendix stump following removal of the appendix. The proper management of the stump is important to prevent serious postoperative complications such as fecal contamination and peritonitis [2-5].

In the literature there are studies showing; simple ligation by open appendectomy simplifies the technical procedure, shortens the operation time and do not produces a deformation of the ceacal wall [2].

In addition to that Roeder has published that $88 \%$ of the needles and remaining pieces of suture gave positive growths on culture media, clearly proving that the needle had penetrated one or more times the mucous membrane of the coecum during purse string suture [6]. 
Citation: Sanal M (2017) Open Appendectomy in Children: Double Ligation Versus Stump Inversion. Int J Surg Surgical Porced 2: 120. doi: https:/doi. $\operatorname{org} / 10.15344 / 2456-4443 / 2017 / 120$

Page 3 of 3

Another subject that we would like to discuss here is the issue of whether laparoscopic appendectomy shall be the substitute for an open appendectomy.Advancements in minimal invasive surgery have resulted in application of these techniques even in children.

Regarding to the study of Namir Kathkhouda et.al there is no significant advantage over open appendectomy compared to laparoscopic appendectomy, therefore the choice of the procedure should be based on surgeon and/or patient preference [7].

We argue that, especially in educational institutions such as surgical training university clinics both methods shall be continued to be in place [8].

\section{Conclusions}

Many studies on simple ligation versus stump inversion in literature puts forward that there is no significant difference in between these two techniques[1-5].

Hence, we aimed at re-evaluating this topic in light of our own findings in childhood.

On our study regarding to the complications we did not observe any difference in between these two techniques.

In conclusion; cconsidering the main surgical principle of "the preference of the more simple technique", we believe that preference of double ligation technique is more appropriate while performing an open appendectomy.

\section{Competing Interests}

The authors declare that they have no competing interests.

\section{References}

1. Neves LJVA, Wainstein AJA, Wallace CM, Dias Costa FP, et al. ( 2011) Simple ligation or ligationand purse string invagination for the treatmentof the appendiceal stump: a prospective, randomized trial. ABCD arq bras cir dig 24: 1-7.

2. Houben F, Willmen HR (1998) Simplified appendectomy without stump embedding. Experiences of 20 years conventional and 5 years laparoscopic application. Chirurg 69: 66-70.

3. Street D, Bodai BI, Owens LJ, Moore DB, Walton CB, et al. (1988) Simple ligation vs stump inversion in appendectomy. Arch Surg 123: 689-690.

4. Engström L, Fenyö G (1985) Appendicectomy: assessment of stump invagination versus simple ligation: a prospective, randomized trial. $\mathrm{Br}$ Surg 72: 971-972.

5. Blanc B, Pocard M (2009) Surgical techniques of appendectomy for acute appendicitis. J Chir (Paris) 146: 22-31.

6. Baldwin JF (1932) The prevention of fecal fistula after appendectomy. Ann Surg 95: 704-714.

7. Kathkouda N, Mason RJ, Towfigh S, Gevorgyan A, Essani R (2005) Laparoscopic versus open appendectomy. Ann Surg 242: 439-450.

8. Lee SL, Yaghoubian A (2010) Comparison of pediatric appendicitis outcomes between teaching and nonteaching hospitals. J Ped Surg 45 $894-897$. 